\title{
The relative risk of mortality to the population on the Krasnoyarsk in the period when the air quality standards are exceeded
}

\author{
Daria A. Chernykh ${ }^{1,2}$, Ekaterina N. Bel'skaia ${ }^{2}$ and Olga V. Taseiko ${ }^{1}$ \\ ${ }^{1}$ Krasnoyarsk Branch of FRC ICT, Krasnoyarsk, Russia \\ ${ }^{2}$ Reshetnev Siberian State University of Science and Technology, Krasnoyarsk, Russia
}

\begin{abstract}
A study was carried out to assess the effect of concentrations of particulate matter $\left(\mathrm{PM}_{10}\right)$, nitrogen dioxide $\left(\mathrm{NO}_{2}\right)$ and formaldehyde $(\mathrm{F})$ exceeding the MPC on the mortality rate of the population of the city of Krasnoyarsk for 10 years (from 2000 to 2004 and from 2014 to 2018). The relative increase in mortality from exposure to the pollutants under study was determined using the relative risk model.
\end{abstract}

Keywords

Air quality, formaldehyde, nitrogen dioxide, particulate matter, population mortality, relative risk.

\section{Introduction}

Today, many Russian cities are facing high levels of atmospheric pollution. Russia depends on coal for electricity production, and coal-fired power plants emit a lot of harmful substances and a large number of solid fractions. The fastest growing source of atmospheric pollution in cities is the emissions of motor vehicles, a lot of volatile organic compounds are introduced into the atmosphere by industry.

In addition to climatic parameters, environmental factors also adversely affect the human body. The impact of climate change in cities is combined with the adverse health impact of polluted ambient air. In the context of the influence of meteorological factors on the health of the population, especially in areas with technogenic pollution, it is necessary to assess the modifying effect of the influence of air pollutants (Particulate matter, Sulfur dioxide, Nitrogen dioxide, Nitrogen oxide, Carbon monoxide and other substances included in the monitoring program) [1].

The industrial enterprises emissions of energy systems and transport into the atmosphere, reservoirs and subsurface have reached such volumes that in a number of regions of the globe, pollution levels significantly exceed the permissible sanitary standards. Every year, about 200 billion tons of rocks are extracted from the earth's interior, more than 9 billion tons of conventional fuels are burned, up to 3 billion tons of pesticides are dispersed in the fields, etc. The problem of environmental pollution by anthropogenic toxicants is particularly acute; the

SDM-2021: All-Russian conference, August 24-27, 2021, Novosibirsk, Russia

$\bigoplus$ da_chernykh@inbox.ru (D.A. Chernykh)

(c) (i) $\odot 2021$ Copyright for this paper by its authors. Use permitted under Creative Commons License Attribution 4.0 International (CC BY 4.0).

$[$ CEUR Workshop Proceedings (CEUR-WS.org) 
annual intake of nitrogen oxides is 65 billion tons, etc. And as a result - pollution of the body with toxic substances and violation of the endoecological balance [2, 3, 4, 5, 6, 7].

Anthropogenic pollution of the environment has a pronounced impact on the population health formation. The contribution of anthropogenic factors to the formation of health deviations ranges from $10 \%$ to $57 \%$. Assessing the significance of environmental pollution by the biological responses of the human body in terms of health is more objective than comparing the concentrations of individual pollutants with hygienic standards, since it integrally takes into account the influence of all, including unidentified pollutants, their complex and combined effect on the human body [8].

Focuses of "endoecological disease" are formed as a kind of epidemic. Environmental poisoning has led to mass degradation of health, adaptation systems have become defenseless against such an anthropogenic load, and this process is aggravated by social and economic difficulties [2].

According to experts of the World Health Organization, 23\% of all diseases and 25\% of all cancer cases are caused by environmental factors, including atmospheric pollution $[4,5,9,10,11]$. Chemical pollution of atmospheric air has a particularly pronounced effect on the health of the most sensitive groups of the population - children and adolescents. In these conditions, the problems of human ecology, the prevention of disease rate, the protection and promotion of public health, the improvement of the environment are of particular relevance [12, 13, 14].

The child's respiratory system is the main target for air pollutants. They cause a wide range of acute and chronic effects, either as a single risk factor, or in combination with other external agents and/or characteristics of the child's susceptibility. Although there is increasing evidence from epidemiological studies of short-term exposure to air pollutants on children's health, very few studies have considered whether exposure to pollutants can initiate asthma, as has been shown for passive smoking. There is evidence from animal studies and "in vitro" studies that support the opinion that a high level of atmospheric air pollution increases the risk of developing lung diseases in children.

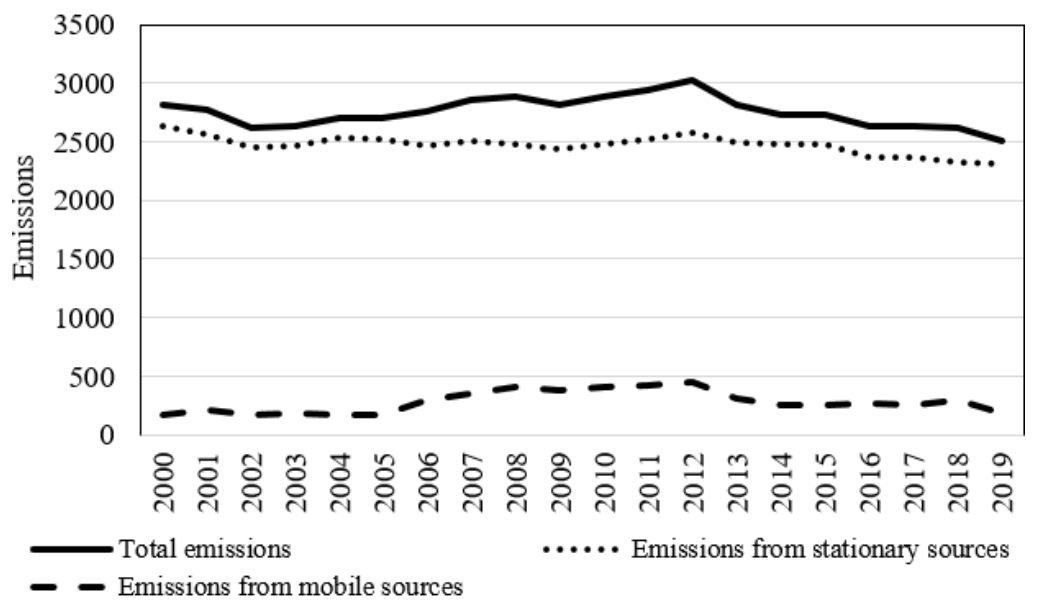

Figure 1: The dynamics of total emissions of pollutants into the atmosphere in the Krasnoyarsk Territory for the period 2000-2019, thousand tons per year [18]. 
Today, a significant number of studies have been conducted aimed at identifying the impact degree of environmental pollution levels on the health of the population. In most cases, the relationship between the concentrations of harmful substances and the disease rate of children was studied. There are not enough studies to assess the correlation between the qualitative composition, concentrations of harmful substances and the health of the population. At the same time, it is very important to assess the reaction of the body, with varying degrees of environmental stress, to establish the degree of dependence and the influence strength for each of the factors, their contribution to changing the health status of the population in specific conditions $[14,15,16,17]$.

The total number of economic subjects and other activities that emit pollutants into the atmospheric air and registered on the territory of the Krasnoyarsk Territory amounted to 2.211, of which 2.150 are legal entities and 61 are individual entrepreneurs. Figure 1 shows the dynamics of total emissions of pollutants into the atmosphere in the Krasnoyarsk Territory for the period 2000-2019 [18].

\section{Materials and methods}

To determine the relative increase in mortality from negative events over the background (expected for these calendar dates) mortality, the relative risk $(R R)$ of mortality was calculated. If the length of the negative impact $N$ lasted from day $D$ to $D+N-1$, then the relative risk was calculated as the average daily mortality over the exposure period divided by the background mortality $M_{D}^{\Phi}$, which is taken on the first day of exposure. Due to the fact that the presence of a lag between an adverse event and mortality is allowed, the relative risk of mortality is calculated as a maximum of several $R R$ values calculated at various lags from zero to the maximum allowable lag $L$ [19]

$$
R R_{L}=\max _{j=0, \ldots, L} \frac{\sum_{i=j}^{N-1+j} M_{D+i+j}}{\left.N M_{(} D+j\right)^{\Phi}} .
$$

For further analysis, only those mortality rates were used, the relative risks of which were recognized as statistically significant at the $95 \%$ level.

\section{The results of the study}

To solve this problem, a database of mortality indicators presented by the Federal State Statistics Service was used. The paper considered the daily mortality in Krasnoyarsk for 10 years (from 2000 to 2004 and from 2014 to 2018) (in the age groups 30-44, 45-59, 60-74, 75+) from the most common diseases characterized by sensitivity to climatic factors:

- diseases of the circulatory system;

- diseases of the respiratory system;

- diabetes mellitus. 
Data on the daily concentration of pollutants in the city of Krasnoyarsk were provided by the Federal Service for Hydrometeorology and Environmental Monitoring. To assess the relative risk, work was carried out to develop the structure of the database and to fill it.

One of the most dangerous pollutants of atmospheric air is ozone $\left(\mathrm{O}_{3}\right)$, which belongs to the first hazard class and is an essential component of photochemical smog. The increased level of ground-level ozone is observed only in sunny hot weather. The inhalation effect of the substance on the body is accompanied by irritation of the respiratory organs, a decrease in

\section{Table 1}

The relative risk of mortality for women during the period of exposure exceeding the MPC for nitrogen dioxide.

\begin{tabular}{ccccccc}
\hline \multirow{2}{*}{ Death causes } & \multirow{2}{*}{ Groups of age, years } & \multicolumn{2}{c}{ from } & 2000 to 2004 & \multicolumn{2}{c}{ from 2014 to 2018 } \\
& & $R R$ & $95 \% \mathrm{Cl}$ & $R R$ & $95 \% \mathrm{Cl}$ \\
\hline & $30-44$ & 1.38 & $1.14-1.65$ & - & - \\
Diseases of the circulatory system & $45-59$ & 2.00 & $1.44-3.15$ & 1.49 & $1.29-1.74$ \\
& $60-74$ & 1.83 & $1.59-2.11$ & 1.64 & $1.44-1.88$ \\
& $75+$ & 1.97 & $1.61-2.77$ & 1.76 & $1.56-2.02$ \\
\hline \multirow{2}{*}{ Diseases of the respiratory system } & $30-44$ & - & - & - & - \\
& $45-59$ & 1.50 & $1.25-1.81$ & - & - \\
& $60-74$ & 1.50 & $1.23-1.82$ & 1.50 & $1.24-1.81$ \\
& $75+$ & 1.50 & $1.23-1.82$ & 1.49 & $1.31-1.71$ \\
\hline & $30-44$ & - & - & - & - \\
Diabetes mellitus & $45-59$ & - & - & - & - \\
& $60-74$ & 1.42 & $1.21-1.66$ & - & - \\
& $75+$ & - & - & 1.63 & $1.32-2.01$ \\
\hline
\end{tabular}

\section{Table 2}

The relative risk of mortality for men during the period of exposure exceeding the MPC for nitrogen dioxide.

\begin{tabular}{cccccc}
\hline \multirow{2}{*}{ Death causes } & \multirow{2}{*}{ Groups of age, years } & \multicolumn{2}{c}{ from 2000 to 2004} & \multicolumn{2}{c}{ from 2014 to 2018 } \\
& & $R R$ & $95 \% \mathrm{Cl}$ & $R R$ & $95 \% \mathrm{Cl}$ \\
\hline \multirow{3}{*}{ Diseases of the circulatory system } & $30-44$ & 1.92 & $1.46-2.59$ & 1.36 & $1.18-1.57$ \\
& $45-59$ & 1.93 & $1.44-3.73$ & 1.56 & $1.38-1.77$ \\
& $60-74$ & 2.02 & $1.68-2.82$ & 1.87 & $1.62-2.17$ \\
& $75+$ & 1.78 & $1.51-2.13$ & 1.89 & $1.63-2.2$ \\
\hline \multirow{3}{*}{ Diseases of the respiratory system } & $30-44$ & 1.67 & $1.3-2.17$ & - & - \\
& $45-59$ & 2.26 & $1.51-3.62$ & 1.50 & $1.25-1.8$ \\
& $60-74$ & 1.45 & $1.26-1.67$ & 1.44 & $1.24-1.69$ \\
& $75+$ & 2.00 & $1.57-2.55$ & 1.44 & $1.27-1.66$ \\
\hline \multirow{2}{*}{ Diabetes mellitus } & $30-44$ & - & - & - & - \\
& $45-59$ & - & - & - & - \\
& $60-74$ & - & - & - & - \\
& $75+$ & - & - & - & - \\
\hline
\end{tabular}


lung functions, the development of asthma and allergies, as well as a significant decrease in immunity to infections $[1,20]$. Due to the fact that ozone measurements are not carried out at the posts of the state observation network in the cities of the Krasnoyarsk Region, data on the concentrations of nitrogen dioxide and formaldehyde as ozone precursors were used in this study.

The relative risk of mortality was estimated for concentrations exceeding the Maximum Permissible Concentrations of the following pollutants: particulate matter $\left(\mathrm{PM}_{10}\right)$, nitrogen dioxide $\left(\mathrm{NO}_{2}\right)$ and formaldehyde $(\mathrm{F})$. Tables 1-6 show the obtained values.

Table 3

The relative risk of mortality for women during the period of exposure exceeding the MPC for $\mathrm{PM}_{10}$.

\begin{tabular}{ccccccc}
\hline \multirow{2}{*}{ Death causes } & \multirow{2}{*}{ Groups of age, years } & \multicolumn{2}{c}{ from } & 2000 to 2004 & \multicolumn{2}{c}{ from 2014 to 2018} \\
& & $R R$ & $95 \% \mathrm{Cl}$ & $R R$ & $95 \% \mathrm{Cl}$ \\
\hline & $30-44$ & 1.73 & $1.34-2.25$ & - & - \\
Diseases of the circulatory system & $45-59$ & 1.91 & $1.43-2.73$ & 1.48 & $1.28-1.71$ \\
& $60-74$ & 1.88 & $1.63-2.18$ & 1.60 & $1.40-1.84$ \\
& $75+$ & 2.00 & $1.63-2.76$ & 1.78 & $1.57-2.05$ \\
\hline \multirow{2}{*}{ Diseases of the respiratory system } & $30-44$ & - & - & - & - \\
& $45-59$ & 1.58 & $1.30-1.92$ & - & - \\
& $60-74$ & 1.63 & $1.34-1.97$ & 1.50 & $1.24-1.82$ \\
& $75+$ & 1.50 & $1.23-1.82$ & 1.48 & $1.30-1.69$ \\
\hline & $30-44$ & - & - & - & - \\
& $45-59$ & - & - & - & - \\
& $60-74$ & - & - & - & - \\
& $75+$ & 1.36 & $1.14-1.63$ & 1.58 & $1.29-1.94$ \\
\hline
\end{tabular}

Table 4

The relative risk of mortality for men during the period of exposure exceeding the MPC for $\mathrm{PM}_{1} 0$.

\begin{tabular}{ccccccc}
\hline \multirow{2}{*}{ Death causes } & \multirow{2}{*}{ Groups of age, years } & \multicolumn{2}{c}{ from 2000 to 2004} & \multicolumn{2}{c}{ from 2014 to 2018} \\
& & $R R$ & $95 \% \mathrm{Cl}$ & $R R$ & $95 \% \mathrm{Cl}$ \\
\hline \multirow{3}{*}{ Diseases of the circulatory system } & $30-44$ & 2.07 & $1.46-3.12$ & 1.30 & $1.14-1.48$ \\
& $45-59$ & 1.85 & $1.44-3.28$ & 1.52 & $1.34-1.72$ \\
& $60-74$ & 1.96 & $1.66-2.50$ & 1.85 & $1.61-2.14$ \\
& $75+$ & 1.74 & $1.49-2.07$ & 1.90 & $1.64-2.22$ \\
\hline \multirow{2}{*}{ Diseases of the respiratory system } & $30-44$ & 1.66 & $1.27-2.21$ & - & - \\
& $45-59$ & 2.18 & $1.46-3.51$ & 1.46 & $1.22-1.74$ \\
& $60-74$ & 1.56 & $1.30-1.86$ & 1.46 & $1.26-1.71$ \\
& $75+$ & 1.50 & $1.23-1.82$ & 1.45 & $1.27-1.66$ \\
\hline & $30-44$ & - & - & - & - \\
\hline
\end{tabular}


Table 5

The relative risk of mortality for women during the period of exposure exceeding the MPC for formaldehyde.

\begin{tabular}{ccccccc}
\hline \multirow{2}{*}{ Death causes } & \multirow{2}{*}{ Groups of age, years } & \multicolumn{2}{c}{ from } & 2000 to 2004 & \multicolumn{2}{c}{ from 2014 to 2018} \\
& & $R R$ & $95 \% \mathrm{Cl}$ & $R R$ & $95 \% \mathrm{Cl}$ \\
\hline & $30-44$ & 1.73 & $1.34-2.25$ & - & - \\
Diseases of the circulatory system & $45-59$ & 1.96 & $1.43-2.90$ & 1.46 & $1.26-1.69$ \\
& $60-74$ & 1.86 & $1.62-2.16$ & 1.63 & $1.43-1.88$ \\
& $75+$ & 2.02 & $1.64-2.76$ & 1.80 & $1.58-2.07$ \\
\hline \multirow{2}{*}{ Diseases of the respiratory system } & $30-44$ & - & - & - & - \\
& $45-59$ & 1.47 & $1.23-1.76$ & - & - \\
& $60-74$ & 1.55 & $1.28-1.87$ & 1.50 & $1.24-1.81$ \\
& $75+$ & 1.50 & $1.26-1.79$ & 1.49 & $1.31-1.70$ \\
\hline & $30-44$ & - & - & - & - \\
& $45-59$ & - & - & - & - \\
& $60-74$ & 1.50 & $1.27-1.7$ & - & - \\
\hline
\end{tabular}

\section{Table 6}

The relative risk of mortality for women during the period of exposure exceeding the MPC for formaldehyde.

\begin{tabular}{cccccc}
\hline \multirow{2}{*}{ Death causes } & \multirow{2}{*}{ Groups of age, years } & \multicolumn{2}{c}{ from 2000 to 2004} & \multicolumn{2}{c}{ from 2014 to 2018} \\
& & $R R$ & $95 \% \mathrm{Cl}$ & $R R$ & $95 \% \mathrm{Cl}$ \\
\hline & $30-44$ & 2.05 & $1.46-3.02$ & 1.39 & $1.19-1.61$ \\
& $45-59$ & 1.88 & $1.46-3.05$ & 1.55 & $1.37-1.76$ \\
Diseases of the circulatory system & $60-74$ & 1.94 & $1.64-2.47$ & 1.85 & $1.61-2.14$ \\
& $75+$ & 1.77 & $1.51-2.11$ & 1.87 & $1.62-2.17$ \\
\hline \multirow{2}{*}{ Diseases of the respiratory system } & $30-44$ & 1.68 & $1.28-2.22$ & 2.00 & $1.53-2.62$ \\
& $45-59$ & 2.38 & $1.52-3.99$ & 1.47 & $1.23-1.76$ \\
& $60-74$ & 1.52 & $1.27-1.82$ & 1.42 & $1.22-1.65$ \\
& $75+$ & 1.75 & $1.40-2.19$ & 1.44 & $1.26-1.65$ \\
\hline & $30-44$ & - & - & - & - \\
Diabetes mellitus & $45-59$ & - & - & - & - \\
& $60-74$ & - & - & - & - \\
\hline
\end{tabular}

The greatest negative impact of the studied factors falls on the period from 2000 to 2004 . The relative risk of mortality during the period of exceeding the maximum permissible concentration of formaldehyde in the atmospheric air is higher than when the maximum permissible concentration of nitrogen dioxide and particulate matter is exceeded. Men, as well as the population with diseases of the circulatory system, in the age group 45-59 are most exposed to the negative effects of pollutants. Indicators of the relative risk of mortality from diseases of the circulatory system are higher in women, from respiratory diseases are higher in men. 
The greatest negative impact from exposure to concentrations exceeding the MPC for nitrogen dioxide was found for women in the age groups from 45 to 59 and from 75 years and older (with diseases of the circulatory system), for men - from 45 to 59 years (with respiratory diseases).

The greatest negative impact from exposure to concentrations exceeding the MPC for PM10 was found for women in the age group from 45 to 59 years and $75+$ (with diseases of the circulatory system), for men - from 45 to 59 years (with respiratory diseases).

The greatest negative impact from exposure to concentrations exceeding the MPC for formaldehyde was found for women in the age group from 45-59 years and 75+ (with diseases of the circulatory system), for men - from 45 to 59 years (with respiratory diseases).

\section{Conclusion}

As a result of the conducted research, it was revealed:

- the greatest negative impact of the studied factors falls on the period from 2000 to 2004;

- the relative risk of mortality during the period of exceeding the maximum permissible concentration of formaldehyde in the atmospheric air is higher than when the maximum permissible concentration of nitrogen dioxide and particulate matter is exceeded;

- men, as well as the population with diseases of the circulatory system, in the age group 45-59 are most exposed to the negative effects of pollutants;

- indicators of the relative risk of mortality from diseases of the circulatory system are higher in women, from respiratory diseases are higher in men.

Today, the mortality rate in Russia is much higher than in European countries, but according to most researchers, there are significant reserves for reducing its level. Research in the field of impact assessment and monitoring of the air pollution effects on public health will make it possible to make more accurate forecasts of mortality from exposure to pollutants in the future. Reducing the level of atmospheric pollution is one of the most effective ways to increase life expectancy in Russia.

\section{Acknowledgments}

The reported study was funded by Russian Foundation for Basic Research, Government of Krasnoyarsk Territory, Krasnoyarsk Regional Fund of Science, to the research project No. 19-413-240013 "Risk assessment methodology caused by environmental factors on population health and mortality in industrial agglomerations".

\section{References}

[1] MR 2.1.10.0057-12.2.1.10. The state of health of the population in connection with the state of the environment and living conditions of the population. Assessment of the risk and damage from climate change affecting the increase in morbidity and mortality in high-risk populations. Approved 17.01.2012. $36 \mathrm{p}$.

[2] Leshchuk S.I., Ochirzhapova D.C. Assessment of the impact of polluted atmospheric air on public health // Bulletin of Siberian Academy of Law, Economics and Management. 2012. No. 1(5). P. 64-67. 
[3] Dautov F.F. Study of public health in relation to environmental factors. Kazan': Izdatel'stvo KGU, 1990. 113 p.

[4] SHamsiyarov N.N., Galeev K.A., Hakimova R.F. et al. Quantitative assessment of the influence of atmospheric air pollutants on the incidence of acute respiratory infections of the upper respiratory tract in children // Hygiene and Sanitation. 2002. No. 4. P. 11-13.

[5] Dautov F.F. et al. Environment and health. Kazan': Dom pechati, 2001. 360 p.

[6] Efimova P.V. et al. Medical and environmental risks of a modern city. Bratsk: BrGU, 2008. $196 \mathrm{p}$.

[7] Leshchenko L.A. et al. Living conditions and health of the population of the Irkutsk region. Irkutsk: VS NC SO RAMN, 2001. $224 \mathrm{p}$.

[8] G 2.1.10.1920-04 Guidelines for Assessing Public Health Risks from Exposure to Chemicals Polluting the Environment. Approved 05.03.2004. 170 p.

[9] Balabina N.M. Influence of atmospheric air pollution on the primary morbidity of the adult urban population with anemia // Acta Biomedica Scientifica. 2005. No. 1. P. 116-119.

[10] Novikova S.M., Skvorcova N.S., Kislicin V.A., SHashina T.A. Impact of short-term changes in weather conditions on public health risk from air pollution // Hygiene and Sanitation. 2007. No. 5. P. 26-28.

[11] Onishchenko G.G. Urban environment and human health // Hygiene and Sanitation. 2007. No. 5. P. 3-4.

[12] Kolesnikova L.I. et al. Assessment of health disorders and developmental microanamalies in children // Byulleten' SO RAMN. 2008. No. 1(129). P. 26-29.

[13] Pinegin B.V., Bajmukanova G.P., Pechurkina N.S. Environmental immunodeficiency: Immunogenetic aspects of its development and correction // Vestnik RAMN. 1994. No. 4. P. 20-28.

[14] Savilov E.D., Il'ina O.V. Infectious pathology in conditions of technogenic pollution of the environment. Novosibirsk: Scince, 2010. 248 p.

[15] Dautov F.F., SHimsiyarova N.N., Hakimova R.F. Influence of polluted atmospheric air on the incidence of acute respiratory viral infections in children // Hygiene and Sanitation. 2003. No. 4. P. 62-64.

[16] Musijchuk Yu.I., Lomov O.P., Kudryavcev V.M. Methodology for a comprehensive assessment of the health status of the population during social and hygienic monitoring // Hygiene and Sanitation. 2008. No. 3. P. 91-92.

[17] SHeshunov I.V. et al. The dependence of the incidence of the population on specific industrial emissions // Hygiene and Sanitation. 1999. No. 3. P. 5-9.

[18] State report "On the state and protection of the environment in the Krasnoyarsk Territory in 2019". Krasnoyarsk: Ministerstvo Ekologii i Racional'nogo Prirodopol'zovaniya Krasnoyarskogo Kraya, 2020. 314 p.

[19] Varakina Zh.L., Yurasova E.D., Revich B.A. et al. Influence of air temperature on the mortality rate of the population of Arkhangelsk in 1999-2008 // Human Ecology. 2011. No. 6. P. 115-127.

[20] Milyaev V.A., Kotel'nikov S.N. Poisonous ozone. New environmental threat to Russia // Ekologiya i Zhizn'. 2008. No. 2(75). P. 52-56. 